\title{
Nanoscale
}

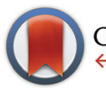

CrossMark \&lick for updates

Cite this: Nanoscale, 2016, 8, 8058

\section{Applicability of avidin protein coated mesoporous silica nanoparticles as drug carriers in the lung $\dagger$}

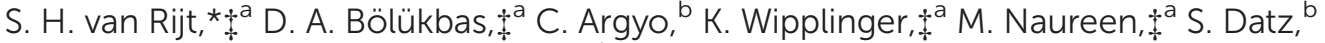 \\ O. Eickelberg, $\star^{a}$ S. Meiners, $\neq^{a}$ T. Bein, ${ }^{\star b}$ O. Schmid $\ddagger^{a}$ and T. Stoeger $\star^{a}$
}

Mesoporous silica nanoparticles (MSNs) exhibit unique drug delivery properties and are thus considered as promising candidates for next generation nano-medicines. In particular, inhalation into the lungs represents a direct, non-invasive delivery route for treating lung disease. To assess MSN biocompatibility in the lung, we investigated the bioresponse of avidin-coated MSNs (MSN-AVI), as well as aminated (uncoated) MSNs, after direct application into the lungs of mice. We quantified MSN distribution, clearance rate, cell-specific uptake, and inflammatory responses to MSNs within one week after instillation. We show that amine-functionalized $\left(\mathrm{MSN}-\mathrm{NH}_{2}\right)$ particles are not taken up by lung epithelial cells, but induced a prolonged inflammatory response in the lung and macrophage cell death. In contrast, MSN-AVI COlocalized with alveolar epithelial type 1 and type 2 cells in the lung in the absence of sustained inflammatory responses or cell death, and showed preferential epithelial cell uptake in in vitro co-cultures. Further, MSN-AVI particles demonstrated uniform particle distribution in mouse lungs and slow clearance rates. Thus, we provide evidence that avidin functionalized MSNs (MSN-AVI) have the potential to serve as versatile biocompatible drug carriers for lung-specific drug delivery.

Received 21st June 2015 Accepted 7th March 2016 DOI: $10.1039 / \mathrm{c} 5 \mathrm{nr} 04119 \mathrm{~h}$ www.rsc.org/nanoscale port of a wide variety of cargo molecules. ${ }^{4}$ Importantly, these particles can be selectively functionalized at specific sites within their structure. For example, the particle core offers a site for covalent attachment of fluorescent dye molecules for particle tracking in biological studies. ${ }^{5}$ In addition, the surface of the MSNs can be selectively modified to introduce controlled drug release functions for optimized drug delivery. ${ }^{4}$ For example, in our recent work we developed mesoporous silica nanoparticles with protease-responsive avidin caps for controllable drug release in lung tumour areas. ${ }^{6}$ Due to the tight sealing of the mesopores by the avidin caps and the selective cleavage of these caps at high protease concentrations found in lung tumours, these drug carriers were able to efficiently release a combination of chemotherapeutic drugs in vitro and ex vivo (mouse and human) with high tumour-selectivity. Other interesting examples of functionalized MSNs that have shown in vivo effectiveness include MSNs functionalized with PEG chains, ${ }^{7}$ folic acid, ${ }^{8}$ or transferrin. ${ }^{9}$ Due to their unique properties, MSNs have been considered as promising candidates for next generation nano-medicines. ${ }^{10}$ However, before these carriers can be used in the clinic, their biocompatibility needs to be proven. Although MSNs are generally considered to be biocompatible, several reports suggest that their bioresponse is strongly affected by their size,${ }^{11}$ shape,${ }^{12}$ porosity,${ }^{13}$ and surface chemistry. ${ }^{11,14}$ In addition, the administration route has been found to play an important role for their biodistribution and bioresponse. ${ }^{15}$ Encouragingly, in vivo toxicity 
studies on different types of MSNs administered using several application routes, indicate that the use of these particles is safe for drug delivery purposes, ${ }^{16-20}$ however, not many of these studies deal with the applicability of MSNs directly in the lung.

Direct application of nanoparticles into the lung (i.e. inhalation therapy) would be beneficial for treatment of (chronic) lung diseases such as idiopathic pulmonary fibrosis (IPF), chronic obstructive pulmonary disease (COPD) and asthma, as drugs are directly administered in the target organ. This is advantageous because high local doses at the site of disease (lung) can be accomplished allowing for high efficacy combined with low prevalence of side effects. Moreover, in contrast to oral administered delivery, inhaled drugs bypass the gastrointestinal tract and the liver, avoiding problems associated with drug degradation in these organs and/or stability in blood circulation. Moreover, pulmonary application of drugs presents a non-invasive route for systemic delivery of drugs, since the huge surface area of the alveolar lung epithelium (ca. $100 \mathrm{~m}^{2}$ ) presents an effective portal of entry into the blood stream. Many drug delivery materials such as polymers are commonly accepted as biocompatible for systemic applications, but some have shown to develop adverse cytotoxic and pro-inflammatory properties in the lungs and seem therefore not suited for direct application into the lung. ${ }^{21}$ Moreover, the inflammatory potential of nanoparticles is especially relevant for the treatment of inflammatory lung diseases such as COPD and asthma, as the additional inflammation caused by drug delivery particles could lead to worsening of the symptoms.

Here, we investigated the suitability of direct application of avidin-capped MSNs in the lung, namely their distribution, clearance rate, cell specific uptake, and the inflammatory response induced over the course of one-week time. For that purpose, single high doses (20 or $100 \mu \mathrm{g}$ per mouse) of avidincapped MSNs (MSN-AVI) were instilled in adult BALB/c mice, and their bioresponse after 1, 3, and 7 days was studied. To analyse the impact of the avidin protein coating, we also included non-protein coated MSNs containing propyl amines on the outer shell $\left(\mathrm{MSN}-\mathrm{NH}_{2}\right)$ in the study. Labelling of the particle core with a fluorescent dye (ATTO 633) allowed for whole lung dosimetry as well as cell specific particle tracking in lung cryo-sections and cytospins of bronchoalveolar lavage fluid (BALF) recovered cells. Moreover, supporting studies using in vitro cell cultures were performed. This provided evidence that MSNs capped with avidin are significantly more biocompatible than amino functionalized MSNs as proven by analyses of their inflammation and toxicity profiles, biodistribution, and cell specific internalization rates, and thus hold potential for use in future lung disease therapy.

\section{Materials and methods}

\section{Materials}

Core-shell functionalized MSNs containing thiol groups in the core and propyl amines on the shell ( $\mathrm{MSN}-\mathrm{SH}_{\mathrm{in}} \mathrm{NH}_{2, \mathrm{out}}$ ), avidin coated MSNs (MSN-AVI) and outer shell non-functionalised MSN particles (nonMSN) were synthesized as previously reported. ${ }^{5,6}$

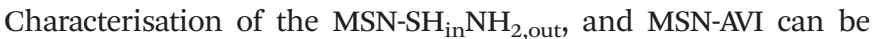
found in Fig. S1. $\dagger$ Details on the synthesis and characterization of non-functionalised MSNs can be found in Fig. S2. $\dagger$

The MSNs suspended in bi-distilled water feature BET surface areas of $1150 \mathrm{~m}^{2} \mathrm{~g}^{-1}\left(\mathrm{MSN}_{-} \mathrm{NH}_{2}\right)$ and $90 \mathrm{~m}^{2} \mathrm{~g}^{-1}$ (MSN-AVI), zeta-potentials of $-30 \mathrm{mV}\left(\mathrm{MSN}-\mathrm{NH}_{2}\right)$ and $+30 \mathrm{mV}$ (MSN-AVI) at $\mathrm{pH} 7.4$, and diameter of $106 \pm 9 \mathrm{~nm}\left(\mathrm{MSN}-\mathrm{NH}_{2}\right)$ and $164 \pm 15 \mathrm{~nm}$ (MSN-AVI). The cores of the MSNs were covalently labelled with ATTO 633 dye and the outer surface contained either $\mathrm{NH}_{2}$ groups $\left(\mathrm{MSN}-\mathrm{NH}_{2}\right)$ or avidin protein (MSN-AVI) covalently attached to the MSNs through a peptide linker. Further details on the synthesis and characterization of the MSNs can be found in the ESI. $\dagger$

Cleaved caspase-3 antibody (Asp175) (Cell signaling, 9661), T1 $\alpha$ antibody (R\&D, AF3244), Pro-SPC antibody (Millipore, AB3786), MAC3 antibody (BD biosciences, BD 550292), were used as received. Bi-distilled water was obtained from a Millipore system (Milli-Q Academic A10). The mouse cell lines, MH-S (murine alveolar macrophages), MLE-12 (murine lung epithelial cells), and CCL-206 (murine lung fibroblasts) were obtained from ATCC (American Type Culture Collection, Manassas, USA). The MLE-12 cell line was maintained in RPMI 1640 medium (Gibco, Life Technologies); the MH-S cell line was maintained in RPMI 1640 medium supplemented with $1 \mathrm{mM}$ Na-pyruvate, $10 \mathrm{mM}$ HEPES, and $50 \mu \mathrm{M}$ 2-ME (all AppliChem). The CCL-206 cell line was maintained in DMEM-F12 medium (Gibco, Life Technologies). All media were supplemented with 10\% FBS (Biochrom) and 1\% penicillin/streptomycin (Life Technologies). All cells were grown at $37{ }^{\circ} \mathrm{C}$ in a sterile humidified atmosphere containing $5 \% \mathrm{CO}_{2}$.

\section{Study design}

The nanoparticles were instilled into Balb/c mice (20 or $100 \mu \mathrm{g})$ and after 1,3 , or 7 days the lungs were excised ( $n=10$ per group). Characterisation of the MSN dispersion over time was performed to assess the agglomeration of the nanoparticles in cell culture medium (RPMI supplemented with FCS). $\mathrm{MSN}-\mathrm{NH}_{2}$ particles of $100 \mathrm{~nm}$ primary size agglomerated after 1 hour to form microparticles of about $1 \mu \mathrm{m}$, while MSN-AVI particles agglomerated to a much lesser extent (Fig. S3A $\dagger$ ). It is important to note that the particles were instilled into the mouse lungs as a homogeneous mixture by vortexing before application (i.e. minimal agglomeration had taken place). Four lungs were directly prepared for cryo-slicing. An additional six mice were used for bronchoalveolar lavage (BAL); BAL fluid (BALF) was collected and separated into cells and supernatant by centrifugation. In addition, BAL recovered cells on cytospins were prepared for all mice for differential cell count. Furthermore, the lavaged lungs and the BAL were used for dosimetry analyses (see Fig. $\mathrm{S} 3 \mathrm{~B} \uparrow$ for a scheme of the experimental set-up).

\section{Methods}

MTT assay. The MTT assay was performed to assess cell viability after exposure to the MSNs in vitro. Briefly, $14 \times 10^{3}$ 
MLE-12 cells per well and $7 \times 10^{3}$ MH-S or CCL-206 cells per well were seeded in 96-well plates. $24 \mathrm{~h}$ after seeding, cells were exposed to $10,50,100,250$, or $500 \mu \mathrm{g} \mathrm{mL} \mathrm{m}^{-1}$ of $\mathrm{MSN}^{-\mathrm{NH}_{2}}$ or MSN-AVI particles for $16 \mathrm{~h}$. After treatment, $10 \mu \mathrm{L}$ of freshly prepared solution of $5 \mathrm{mg}$ thiazolyl blue tetrazolium bromide $\mathrm{mL}^{-1} \mathrm{PBS}$ (Sigma) was added to each well, and the cells were incubated at $37{ }^{\circ} \mathrm{C}$ for $1 \mathrm{~h}$. The supernatant was then aspirated, and the violet crystals were dissolved in $500 \mu \mathrm{L}$ isopropanol $+0.1 \%$ Triton X-100 (both AppliChem). Absorbance was measured at $570 \mathrm{~nm}$, using a Tristar LB 941 plate-reader (Berthold Technologies). Experiments were done in triplicate. Data analyses were performed in Prism GraphPad (version 5.0) software. All values are shown as mean with standard deviation. For comparison of two groups, a one-way ANOVA was performed. A $p$-value lower than 0.05 was considered statistically significant.

Co-culture experiments. MLE-12 cells were labelled with VybrantDiD (Thermo Fisher Scientific, Germany) before they were seeded, according to the procedure described by Burguera et al. ${ }^{22}$ Briefly, MLE-12 cells were incubated for $20 \mathrm{~min}$ with $5 \mu \mathrm{L} \mathrm{mL}{ }^{-1}$ of VybrantDiD. The labelled cells were washed three times with their respective medium and $4 \times 10^{5}$ cells per well were seeded in 6-well plates and incubated for $12 \mathrm{~h}$. After incubation, $2 \times 10^{5} \mathrm{MH}$-S cells per well were seeded in the same 6-well plates and incubated for $4 \mathrm{~h} .50 \mu \mathrm{g} \mathrm{mL}{ }^{-1}$ MSN-AVI or MSN-NH $\mathrm{NH}_{2}$ was added to the wells and the plate was incubated for $16 \mathrm{~h}$. The cells were then trypsinised, washed three times with PBS, and finally suspended in $700 \mu \mathrm{L}$ of PBS. Samples were then analysed by flow cytometry (BD LSRII). MSN uptake in the different cell types was quantified by gating the labelled MLE-12 cells and non-labelled MH-S cells using the APC-A channel (Fig. S5†), and analysing the particle signal (FITC channel) in each gated cell population.

Animal experiments. Animal experiments were carried out according to the German law of protection of animal life and were approved by an external review committee for laboratory animal care. 8-12 week-old female BALB/cAnNCrl mice (Charles River Laboratories, Sulzfeld, Germany) were intratracheally instilled, as described by Stoeger $e t$ al. ${ }^{23} 1,3$, or $7 \mathrm{~d}$ post-instillation mice were sacrificed with an overdose of ketamine (188.3 mg per kg body weight) and xylazin hydrochloride solution (4.1 mg per kg body weight) (bela-pharm, Germany) and their blood was retro-orbitally collected for further investigation. The lungs of 6 mice were lavaged with PBS buffer $\left(37{ }^{\circ} \mathrm{C}\right)$, as previously described. ${ }^{24}$ Cytocentrifuged slides of spun down lavaged cells were prepared for cell differentiation, after staining with May-Grünwald dye. For each mouse two slides were used for cell differentiation counting (200 cells per slide). Two additional sets of BAL cell cytospins were frozen at $-80{ }^{\circ} \mathrm{C}$ for subsequent confocal microscopy analyses. Lavaged lungs were then isolated and frozen for whole lung fluorescence analysis as described below. Four non-lavaged mice lungs from each group were excised and prepared for cryoslicing and immunofluorescent staining.

Cytokine release. In this study, secretions of five cyto-/chemokines (IL-1 $\beta$, TNF- $\alpha$, CXCL1, CXCL5, and CCL2) were investi- gated by ELISA analyses performed with the BAL (DuoSet ELISA, R\&D Systems, Inc., Minneapolis, USA). The assay was performed as previously described. ${ }^{25}$

Histological preparations. After treatments, four mice from each group were anesthetised and sacrificed as aforementioned for histological analyses. Following intubation and diaphragm dissection, lungs were perfused via the right ventricle with sodium chloride solution (Braun Vet Care, Germany). Airways were filled with $\mathrm{Neg}-50^{\mathrm{TM}}$ frozen section medium (Fisher Scientific) at room temperature. Later, the tracheae were knotted, the lungs were excised and transferred into cryomolds (Thermo Scientific) loaded with Neg-50 ${ }^{\mathrm{TM}}$. Samples were left to freeze on dry ice and then stored at $-80^{\circ} \mathrm{C} .14 \mu \mathrm{m}$ thick cryo-sections were sliced with the cryostat (Carl Zeiss Hyrax C 50) and placed on superfrost ultra plus adhesion slides (Thermo Scientific). Immunofluorescence stainings were performed as described below. For hematoxylin and eosin staining, the lungs were placed in $4 \%(\mathrm{w} / \mathrm{v}$ ) paraformaldehyde and processed for paraffin embedding. The deparaffinised $3 \mu \mathrm{m}$ thick sections were stained with hematoxylin and eosin (both Carl Roth, Germany) subsequently, and dehydrated respectively in consecutively grading ethanol and xylene solutions (both Applichem, Germany). Dried slides were mounted in entellan (Merck, Germany).

Immunofluorescence analyses. Lung cryo-sections or cytospins of BAL recovered cells were fixed with methanol $70 \mathrm{vol} \%$ solution for $10 \mathrm{~min}$, washed with PBS, blocked with RotißImmunoBlock (Carl Roth, Germany) for $1 \mathrm{~h}$ at room temperature, and incubated with primary antibody at $4{ }^{\circ} \mathrm{C}$ overnight. Afterwards, lung cryo-sections were washed with PBS, incubated with Alexafluor 488 secondary antibody for $2 \mathrm{~h}$ at room temperature, again washed with PBS and finally stained with DAPI (Sigma-Aldrich). In case phalloidin staining (Life Technologies) was used, lung cryo-sections were incubated with a mixture of phalloidin and DAPI for $30 \mathrm{~min}$ at room temperature directly after the fixation and washing step. Stained lung cryo-sections were mounted using fluorescence mounting medium (DAKO, USA) and analysed using confocal microscopy (LSM710, Carl Zeiss, Germany).

Dosimetry. As the core of the MSNs was labelled with ATTO 633, both the BAL fluid and the lavaged lung tissue were analysed for MSN dosimetry based on quantitative fluorescence analysis at three time points $(1 \mathrm{~d}, 3 \mathrm{~d}, 7 \mathrm{~d})$. While aliquots of the thawed supernatant of the centrifuged BAL could be sampled directly, an aliquot of the cell pellet of the BAL was resuspended in $200 \mu \mathrm{L}$ PBS, vortexed and further diluted with PBS to yield $1000 \mu \mathrm{L}$ of sample. The lavaged lung tissue was homogenized according to the following protocol. A defined volume of PBS $(1200 \mu \mathrm{L}$ minus liquid content of the lung approximated by $1 \mathrm{mg}$ of lung tissue corresponding to $1 \mu \mathrm{L}$ ) was added to the tissue samples. The samples were mechanically homogenized with a high-performance disperser (T10 basic ULTRA-TURRAX $®$ ) at room temperature until no tissue pieces were visible anymore ( $c a .3-5$ min with short breaks to avoid undue heating of the samples). Residual tissue was rinsed off the disperser using $300 \mu \mathrm{L}$ of PBS. Samples were vor- 
texed immediately prior to pipetting four $50 \mu \mathrm{L}$ aliquots (quadruple determination) from each of the samples in a black 96well plate for quantitative fluorescence analysis with a standard multiwell plate reader (Tecan Safire 2; bandwidth of optical filters: $7 \mathrm{~nm}$; excitation and emission wavelength: $630 \mathrm{~nm}$ and $650-670 \mathrm{~nm}$ (average of $650 \mathrm{~nm}, 660 \mathrm{~nm}$ and $670 \mathrm{~nm}$ ), respectively). The fluorescence signals were related to the corresponding MSN mass using standard curves, which were prepared from the BAL and lung tissue of non-exposed mice according to the same protocol described above (cage control).

The dosimetric method presented here was validated using reference mice with a known pulmonary MSN dose as previously described. ${ }^{26}$ In brief, these reference mice received $100 \mu \mathrm{L}$ of the MSN-AVI suspension via intratracheal instillation and were sacrificed immediately after the procedure to avoid dose bias due to partial clearance of the applied MSN-AVI particles from the lung. The actually instilled volume of the MSN-AVI suspension was determined for each mouse by gravimetric analysis of the instillation wear prior and after instillation. ${ }^{26}$ The spectrophotometrically measured amount of MSN-AVI agreed with the applied amount of MSN-AVI within the expected experimental uncertainty of $15 \%$. Finally, $7 \mathrm{~d}$ incubation of MSN-AVI particles in the supernatant of the BAL and subsequent centrifugation revealed that no detectable amount of the fluorescent tracer (ATTO 633) was leaking out of the MSN-AVI. This is a prerequisite for reliable pulmonary dosimetry based on fluorescence analysis.

Native gel (protein corona). To analyze the difference in protein corona formation with respect to the different functionalizations, we performed native PAGE after treating the MSNs with isolated mouse lungs alveolar lining fluid (BALF). $500 \mu \mathrm{L}$ of each MSN (-AVI or -NH2 at a concentration of $1 \mathrm{mg} \mathrm{mL}^{-1}$ ) was centrifuged at $10000 \mathrm{rpm}$ and HBBS medium was removed, the pellet was resuspended in $500 \mu \mathrm{L}$ mouse BAL. $500 \mu \mathrm{L}$ of each MSN particle type in HBBS $1 \mathrm{mg} \mathrm{mL}{ }^{-1}$ was used as control. The samples were incubated at $37{ }^{\circ} \mathrm{C}$ for 16 hours while gently shaking. After the incubation period, the samples were vortexed briefly followed by centrifugation at $18000 \mathrm{rpm}$ for $40 \mathrm{~min}$ at $15{ }^{\circ} \mathrm{C}$. The supernatant was removed and the remaining pellets were washed with PBS (centrifugation at $18000 \mathrm{rpm}$ for $40 \mathrm{~min}$ at $15{ }^{\circ} \mathrm{C}$ after each wash). Finally, the pellet was dissolved in $50 \mu \mathrm{L}$ of PBS and run on a $10 \%$ native gel for 90 minutes at $100 \mathrm{~V}$. The native gel was stained with page blue ${ }^{\mathrm{TM}}$ and the whole gel was imaged using a ChemiDoc imaging system (Bio-rad).

Statistics. All values are presented as mean \pm standard deviation (SD) of six animals per group $(n=6)$, unless otherwise stated. Significant differences between two groups were evaluated by the unpaired two-tailed $t$-test with Welch's correction. Statistical analysis was performed using the program GraphPad Prism 5.0 (GraphPad Software, Inc., La Jolla, CA 92037, USA). Quantification of nanoparticles in cryo-sections or on BAL cytospins was conducted using the IMARISx64 software (version 7.6.4, Bitplane, Switzerland). A $p$-value lower than 0.05 was considered statistically significant.

\section{Results and discussion}

\section{Pulmonary inflammation analyses}

In vivo inflammatory cell recruitment into the airspace was first assessed by BAL differential cell count. Total BAL cell numbers were not significantly different from sham control (PBS) at day 1 , but increased at day 3 for $100 \mu \mathrm{g}$ of MSN-AVI and at day 7 for $100 \mu \mathrm{g}$ of $\mathrm{MSN}-\mathrm{NH}_{2}$ particles (Fig. 1A). These changes are mainly related to the increases in macrophage numbers, which in general represent the majority of BAL leukocytes (Fig. 1C). A particular severe inflammatory response was detected by the acute increase of polymorphonuclear neutrophils (PMNs): after 1 day of treatment with the high dose $(100 \mu \mathrm{g})$ of $\mathrm{MSN}-\mathrm{NH}_{2}$ particles giving rise to $60 \%$ of total BAL cells (Fig. 1B and Table 1). The same treatment with MSN-AVI particles also resulted in a distinct PMN influx into the airspace; however, comparatively less pronounced to what was observed for the MSN-NH $\mathrm{H}_{2}$ particles (33\% of total BAL cells, Fig. 1B). This almost 2 fold higher PMN influx into the alveolar airspace at day 1 after instillation for $\mathrm{MSN}-\mathrm{NH}_{2}$ compared to MSN-AVI particles indicates an improved biocompatibility of the MSN surface due to avidin capping. In addition, for both particle types, a time-dependent resolution of the neutrophilic inflammation was noted, but only for the MSN-AVI particles inflammation had completely resolved after 7 days (Fig. 1B), further indicating improved biocompatibility for MSN-AVI.

In line with that, only $\mathrm{MSN}-\mathrm{NH}_{2}$ instillation resulted in macrophage accumulation in the airspace from day 3 to day 7 (Fig. 1C and Table 1) as well as the formation of giant cells (multinucleated macrophages, Fig. 1D and Table 1), both of which are signs for chronic inflammation and foreign body response. $^{27}$ Lymphocyte numbers remained below 2000 $(<0.5 \%$ of total BAL cells) for all conditions investigated (Fig. S3C $\dagger$ ).

Inflammation caused by $\mathrm{MSN}-\mathrm{NH}_{2}$ was further assessed on the molecular level by BALF cytokine profiling, assessing IL-1 $\beta$, and TNF- $\alpha$ as the major pro-inflammatory master cytokines, CCL2 as classical monocyte/macrophage and CXCL1 and CXCL5 as the most relevant neutrophil chemoattractants. Treatment with $\mathrm{MSN}-\mathrm{NH}_{2}$ caused the highest pro-inflammatory cytokine response; 1 day after treatment yielded high levels of all cytokines investigated (Fig. 1E-I). BALF levels of the two master cytokines for inflammation, IL-1 $\beta$ and TNF $\alpha$, were high during the acute phase after $\mathrm{MSN}-\mathrm{NH}_{2}$, but not after MSN-AVI treatment and returned to baseline levels by day 7 (Fig. 1E and F). Levels of chemokine CCL2, a monocyte attractant, correlated rather with PMN than macrophage numbers and were highest 1 day after $\mathrm{MSN}-\mathrm{NH}_{2}$ treatment (Fig. 1G), where the lowest macrophage numbers were detected (Fig. 1C). This argues for significant macrophage cell death during the acute phase after $\mathrm{MSN}-\mathrm{NH}_{2}$ instillation, causing a depletion of the alveolar macrophage pool uncompensated by the high levels of the CCL2 monocyte/macrophage attractant. The concentrations of the functional murine IL-8 homologues, CXCL1 and -5 (Fig. 1H and I) correlated well with the number of BAL PMNs (Fig. 1B) and showed accordingly higher levels for 
A)

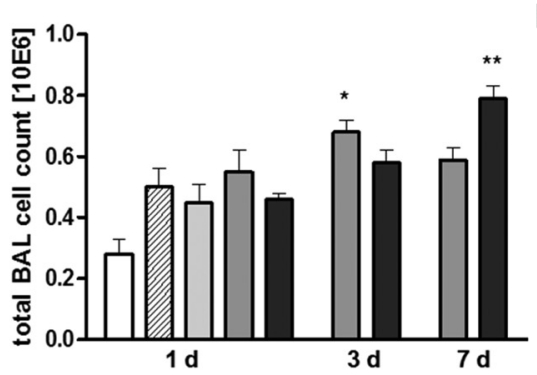

B)

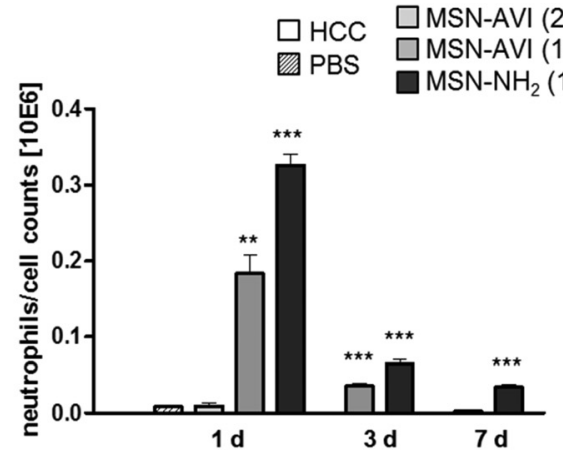

C)

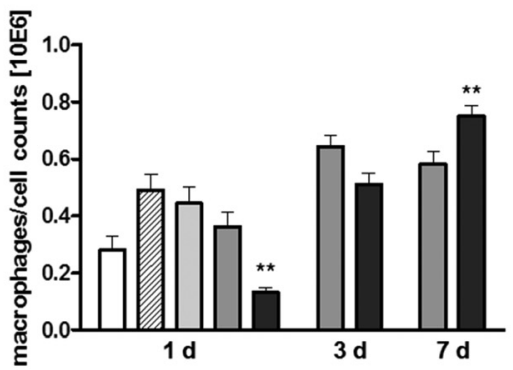

E)

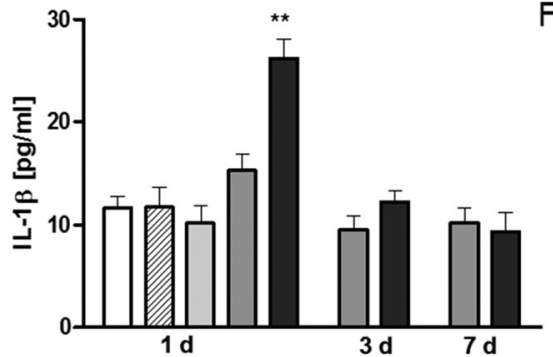

G)

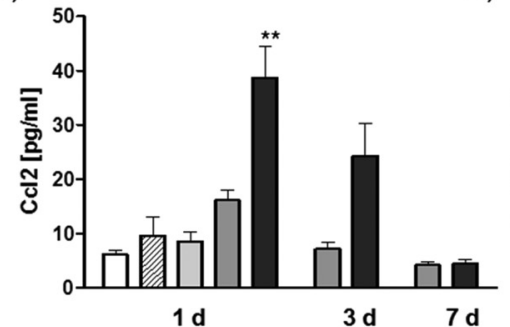

H)

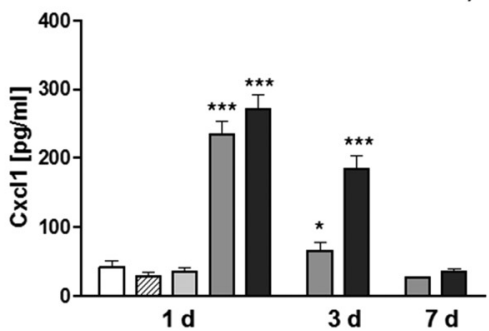

I)
D)

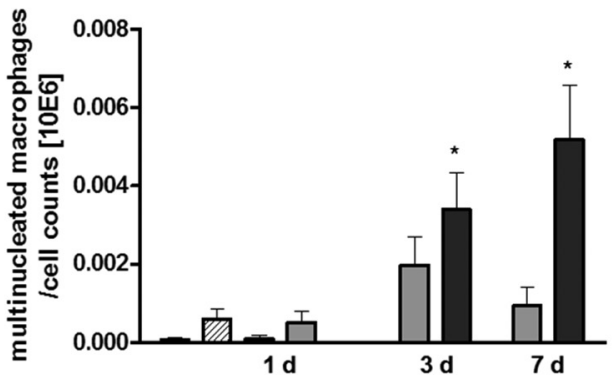

F)
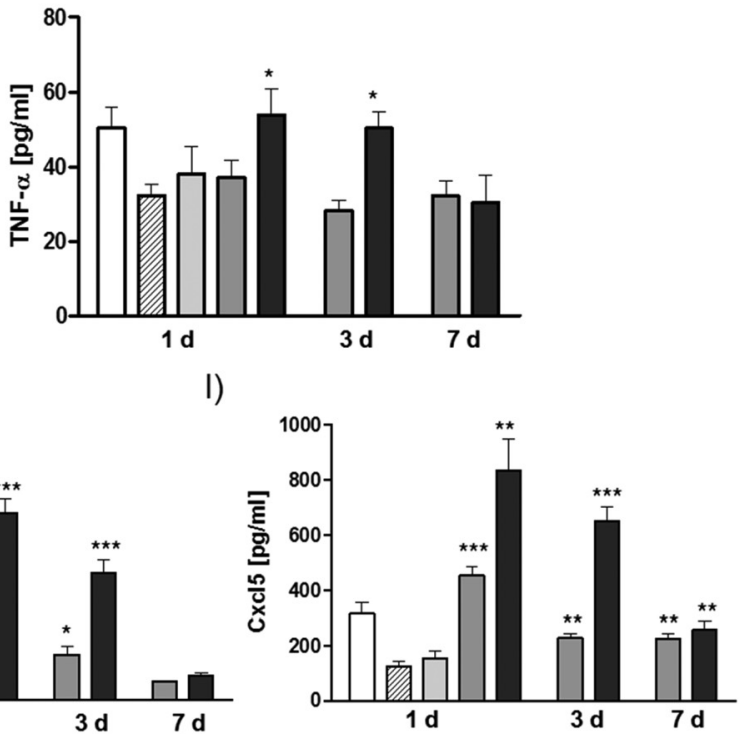

Fig. 1 BAL cell analysis and cytokine release in BALF at three time points after MSN instillation into Balb/c mice. Bronchoalveolar lavage (BAL) cells were counted and dead cells were discriminated by Tryphan blue staining; differentiation was analyzed by May-Grünwald staining. Total BAL cell count is shown in A, total neutrophil numbers in B, macrophage numbers in C, and multinucleated macrophages in D. Release of cytokines was measured in bronchoalveolar lavage fluid (BALF) for each animal in each group, interleukin-1 beta (IL-1 $\beta$ ) is shown in E, TNF- $\alpha$ is shown in F, monocyte chemotactic protein 1 (CCL2) is shown in G, Cxcl1 is shown in $\mathrm{H}$, and Cxcl5 is shown in I. Values are indicated as mean \pm SD, $n=6$, asterisks represent significance compared to PBS control groups (100 $\mu$ L PBS instilled animals) with ${ }^{* * *} p<0.001,{ }^{* *} p<0.01,{ }^{*} p<0.05$. HCC $=$ home cage control (non-treated animals).

MSN-NH $\mathrm{N}_{2}$ than MSN-AVI treated lungs. Elevated levels of the epithelial derived CXCL5 at day 7 could be interpreted as a sign for prolonged epithelial pro-inflammatory response to MSN particles, however similar levels are observed for untreated controls at day 1 , thus questioning a physiological relevance. No evidence for inflammation was detected at the lower dose of $20 \mu \mathrm{g}$ MSN-AVI per mouse, suggesting $1 \mathrm{mg}$ $\mathrm{kg}^{-1}$ as a safe dose for pulmonary applications for this particle type.

The impact of the particle characteristics, agglomeration state, zeta-potential and specific surface area are of particular interest for the development of safe nanocarrier systems for pulmonary drug delivery. Recently, an indirect correlation between the agglomerate size of instilled particles and the 
Table 1 Summary of the inflammatory effects of MSN-NH and MSN-AVI in BAL at 1, 3 and 7 days after instillation. In addition, an overview of the collected cytokine parameters is given

\begin{tabular}{lllllll}
\hline & & $\begin{array}{l}\text { Instilled } \\
\text { amount }(\mu \mathrm{g})\end{array}$ & $\begin{array}{l}\text { PMN cell } \\
\text { count } \times 10^{3}(\%)\end{array}$ & $\begin{array}{l}\text { Macrophages cell } \\
\text { count } \times 10^{3}(\%)\end{array}$ & $\begin{array}{l}\text { Multinucleated macrophages } \\
\text { cell count } \times 10^{3}(\%)\end{array}$ & Detected cytokines \\
\hline $1 \mathrm{~d}$ & $\mathrm{HCC}^{a}$ & - & $0.2(0)$ & $280(100)$ & $0.1(0)$ & - \\
& PBS $^{b}$ & - & $7.9(1.6)$ & $491(98)$ & $0.6(0.1)$ & - \\
& MSN-AVI & 20 & $9.2(2)$ & $444(98)$ & $0.1(0)$ & CXCL5, CXCL1 \\
& MSN-AVI & 100 & $183(33)$ & $363(66)$ & $0.5(0.1)$ & CXCL5, CXCL1, CCL2, IL-1 $\beta$, TNF- $\alpha$ \\
& MSN-NH 2 & 100 & $326(60)$ & $131(29)$ & $0(0)$ & CXCL5, CXCL1 \\
$3 \mathrm{~d}$ & MSN-AVI & 100 & $35(5)$ & $644(95)$ & $1.9(0.3)$ & CXCL5, CXCL1, TNF- $\alpha$ \\
& MSN-NH 2 & 100 & $65(11)$ & $511(88)$ & $3.4(0.6)$ & CXCL5 \\
$7 \mathrm{~d}$ & MSN-AVI & 100 & $2(0.4)$ & $581(99)$ & $0.9(0.2)$ & CXCL5
\end{tabular}

acute inflammatory response was described for different dispersions of nickel-oxide nanoparticles with size distributions ranging from $100 \mathrm{~nm}$ to $4 \mu \mathrm{m} .{ }^{28}$ Based on their findings the authors argued that the reduced biologically accessible surface area of poorly dispersed suspensions might be limiting the bioactivity and toxicity of the instillation delivered nanoparticles. High zeta-potential of nanoparticle dispersions are generally appreciated for their enhanced stability, but have also been associated with increased toxicity and inflammation. ${ }^{29,30}$ As opposed to this broad rule, we show an improved biocompatibility for MSN-AVI preparations characterized by low agglomerate size and even higher zeta-potential as compared to the $\mathrm{MSN}-\mathrm{NH}_{2}$ material. The particle surface of crystalline silica (i.e. quartz), is well known to induce lung inflammation (silicosis) upon inhalation. Toxicity has also been shown for some non-crystalline (amorphous) silica particles when applied directly in the lung, although highly dependent on size, surface and preparation route of the silica particles. ${ }^{31}$ The release of IL-1 $\beta$ from pulmonary macrophages is described as a central mechanism triggering their toxicity in the lung. ${ }^{32}$ In agreement with the latter, the highest levels of IL-1 $\beta$ release, and inflammatory cell accumulation were detected for $\mathrm{MSN}-\mathrm{NH}_{2}$ particles, where the silicate particle surface area is not coated and hidden by the basically charged glycoprotein, avidin. The observation of an increased inflammatory response for $\mathrm{MSN}-\mathrm{NH}_{2}$ compared to MSN-AVI particles suggests that the partially exposed silica surface of the MSN-NH $\mathrm{N}_{2}$ particles, but not the avidin protein covered surface, induces inflammation. The $\mathrm{MSN}-\mathrm{NH}_{2}$ particles have a large BET surface area of $1150 \mathrm{~m}^{2} \mathrm{~g}^{-1}$ and a zeta potential of $-30 \mathrm{mV}$, while MSN-AVI particles have a BET surface area of only $90 \mathrm{~m}^{2} \mathrm{~g}^{-1}$ and a zeta potential of $30 \mathrm{mV}$ (measured at $\mathrm{pH}$ $=7){ }^{6}$ This dramatic difference in accessible surface area and charge indicates that the avidin protein covers the surface of the MSN, thus significantly changing the surface characteristics of the particles. Further analysis of the MSN's incubated with isolated mouse lung alveolar lining fluid (BALF) revealed that $\mathrm{MSN}-\mathrm{NH}_{2}$ particles form a significantly larger protein corona compared to MSN-AVI particles (Fig. S3D †). This may be explained by the partially exposed silica surface of the
MSN-NH $\mathrm{N}_{2}$ particles, compared to the already protein-coated MSN-AVI particles. This result highlights that MSN's coated with a protein corona do not behave similarly compared to MSN particles that have a protein coat that is covalently attached to the surface of the particle. Interestingly, when instilling $100 \mu \mathrm{L}$ of $\mathrm{MSN}-\mathrm{NH}_{2}$ or non-functionalised MSNs (with hydroxyl groups on the surface; nonMSN) into mice, we observed that nonMSN cause significantly less acute inflammation (pulmonary PMNs influx) compared to $\mathrm{MSN}-\mathrm{NH}_{2}$ after $24 \mathrm{~h}$ (Table S1 $\dagger$ ). Both particles have a large BET surface area arguing against surface area as major driver of toxicity in this case. It is possible that the amine groups are responsible for the increased inflammatory effect. Similarly, polystyrene particles with outer $\mathrm{NH}_{2}$ groups have been reported to be more toxic then their hydroxyl counterparts. ${ }^{33-35}$ In addition to their differential functionalities, our observations may also be explained by the fact that $\mathrm{MSN}-\mathrm{NH}_{2}$ particles form larger agglomerates (about $1000 \mathrm{~nm}$ ) compared to MSN-AVI and nonMSN particles (about $200 \mathrm{~nm}$ ) after only a few hours in suspension (Fig. S3A广). Large agglomerates (bigger than $400 \mathrm{~nm}$ ) are more effectively phagocytized by macrophages than endocytosed by epithelial cells. ${ }^{36}$ In addition, the formation of a larger protein corona on MSN- $\mathrm{NH}_{2}$ particles compared to the MSN-AVI (Fig. S3†) may also contribute to enhanced bioactivity and even to the observed increased macrophage particle uptake for the $\mathrm{MSN}-\mathrm{NH}_{2}$. Size-dependent nanoparticle uptake has been observed previously in lung macrophage and epithelial cells. ${ }^{37}$ All in all, our data suggests that avidin protein modified MSNs are safe to use for lung application at $1 \mathrm{mg}$ per $\mathrm{kg}$ dose and induce a minor inflammatory response at $5 \mathrm{mg}$ per $\mathrm{kg}$ dose that completely resolved after 7 days.

\section{Cytotoxicity analysis}

The toxic effects of the two particle types in the mouse model were investigated with cytospins of bronchoalveolar lavage (BAL) cells and on lung cryo-sections (from non-lavaged mice) using immunofluorescence staining. For this approach, cells and tissues were stained with an apoptotic cell marker (cleaved caspase-3, green signal in Fig. 2A). The MSNs, covalently labelled with ATTO 633 dye, could easily be recognised 
A)
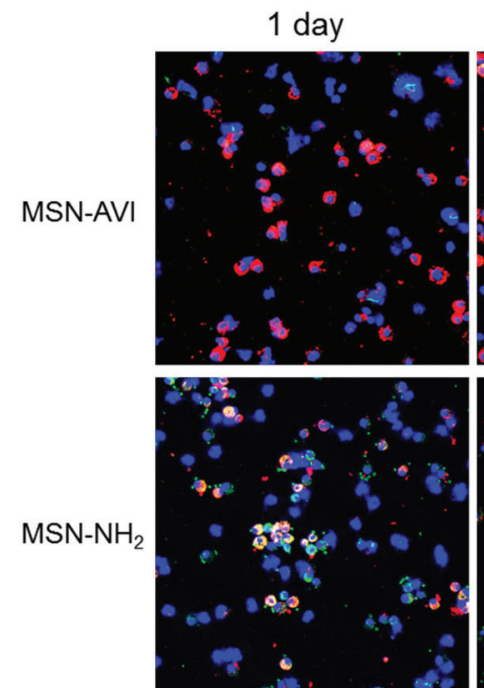

DAPI, MSNs, Cleaved caspase-3

B)

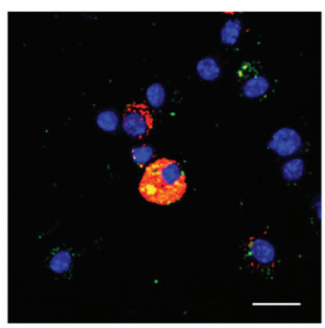

DAPI, MSNs, Cleaved

caspase-3

D)

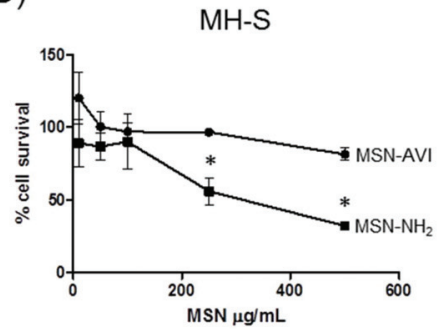

BAL
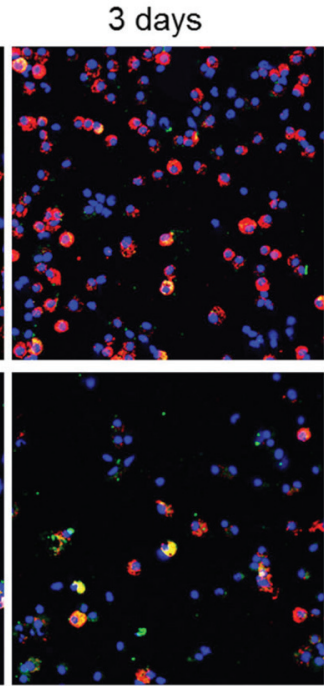

C)

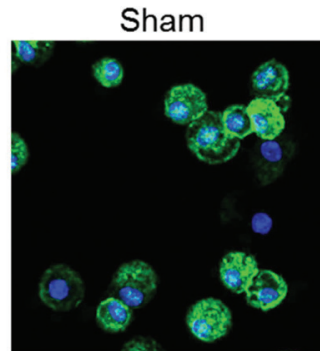

DAPI, MSNs, phalloidin

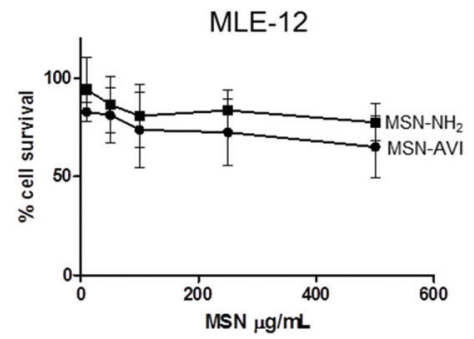

Tissue

7 days
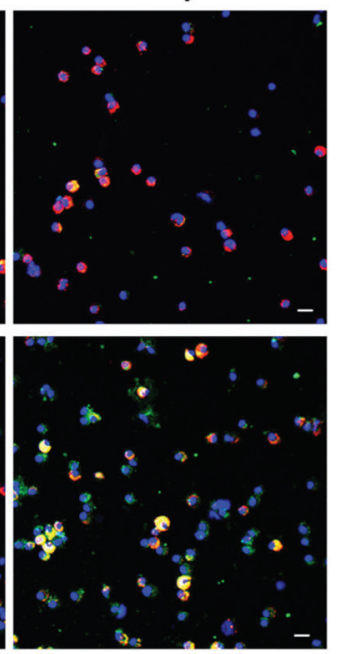

MSN-AVI
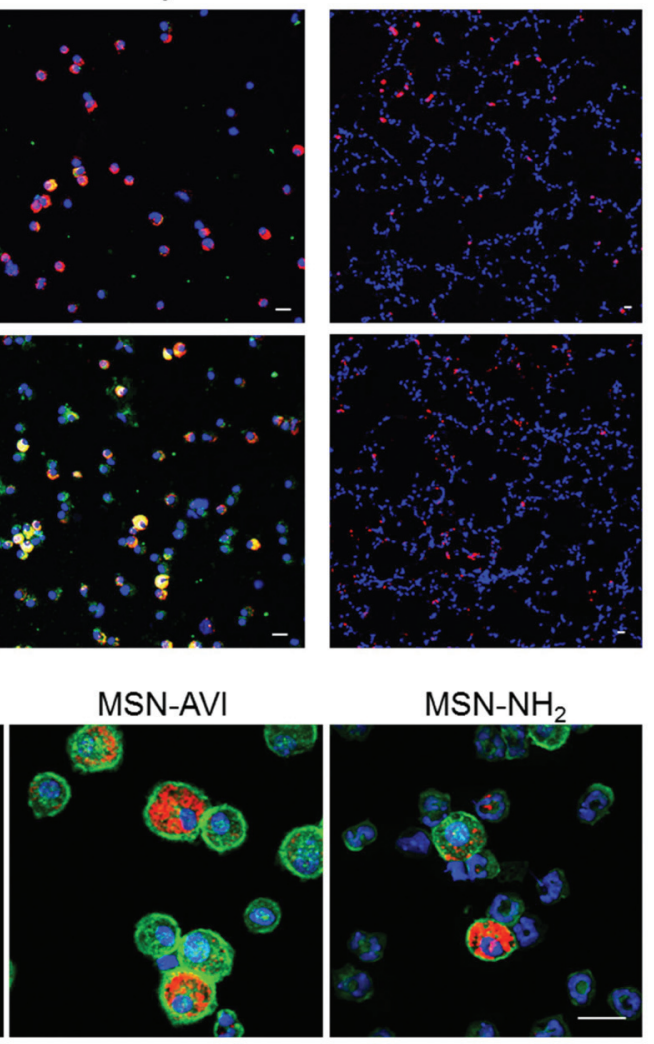

$\mathrm{MSN}-\mathrm{NH}_{2}$

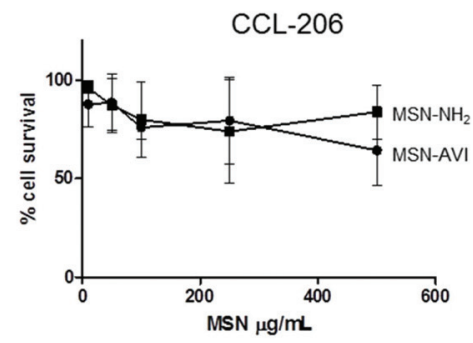

Fig. 2 Cytotoxicity assessment of MSN-AVI and MSN-NH particles. (A) Toxicity of MSN-AVI or MSN-NH 2 particles in Balb/c mice after instillation with $100 \mu \mathrm{g}$ for 1,3 , or 7 days, analyzed from cytospins of BAL cells (left) and lung cryo-slices (right). Cell nuclei are shown in blue (DAPI), ATTO 633

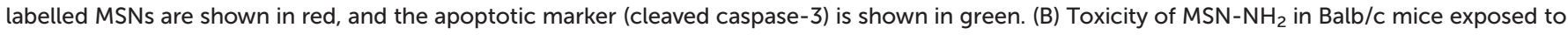
$100 \mu \mathrm{g}$ for 7 days in cytospins of BAL recovered cells using a $63 \times$ objective; high particle loading correlates with toxicity. Yellow staining (in A and B) is due to overlap of MSNs (red) and apoptotic cells (green). (C) MSN uptake in macrophages after 1 day exposure to, from left to right, $100 \mu \mathrm{L}$ PBS, $100 \mu \mathrm{g}$ MSN-AVI or MSN- $\mathrm{NH}_{2}$ (cytoskeleton labelled with phalloidin, green), (D) Cytotoxicity of MSN-AVI and MSN-NH $\mathrm{N}_{2}$ particles as determined by MTT assay in MH-S, MLE-12, and CCL-206 cells after $16 \mathrm{~h}$ of exposure. Values are indicated as mean \pm SD, $n=3$, asterisks represent significance with ${ }^{*} p<0.05$. Scale bar is $20 \mu \mathrm{m}$.

in both the cytospins and the cryo-sections (red signal in Fig. 2A). Exposure to high doses of MSN-AVI particles did not cause any significant apoptotic toxicity in BAL cells, compared to the vehicle/sham control (PBS instilled mice) or the low dose of MSN-AVI (Fig. 2A upper panel, controls are shown in Fig. S4A $\dagger$ ). Significant apoptosis, however, could be observed for BAL cells exposed to $\mathrm{MSN}-\mathrm{NH}_{2}$ particles, which did not subside 7 days after exposure (Fig. 2A lower panel). Neither particle type induced any distinguishable toxicity in lung cryosections of the lavaged lungs (Fig. 2A, right panel). Furthermore, particle uptake and burden of the macrophages correlated with increased apoptosis marker staining (Fig. 2B). Macrophage MSN particle internalization was confirmed with phalloidin staining in confocal microscopy, showing actin (green) encapsulated MSN agglomerates (Fig. 2C). In addition, in in vitro exposure experiments of the three major cell types of 
the lung supported our in vivo observation; only $\mathrm{MSN}-\mathrm{NH}_{2}$ showed significant cytotoxicity towards $\mathrm{MH}-\mathrm{S}$ murine alveolar macrophage cells, whereas no effect was observed in murine lung epithelial (MLE-12) or fibroblast (CCL-206) cell lines at high doses for either material (Fig. 2D). In line with that, also no structural changes of the alveolar microarchitecture could be observed in paraffin lung sections due to particle exposure (Fig. S4B $\dagger$ ). In accord with our pulmonary inflammation analysis, the $\mathrm{MSN}-\mathrm{NH}_{2}$ particles appear to cause selective macrophage toxicity, but no toxicity in lung parenchyma or in epithelial and fibroblast cell lines. It seems therefore likely that a phagocytic uptake of the large $\mathrm{MSN}-\mathrm{NH}_{2}$ agglomerates is required to generate the cytotoxic response while nonprofessional phagocytes might be spared from the harmful effects of non-avidin coated MSNs. In summary, the nanoparticle coating appears to be crucial for their inflammatory and toxic response in the lung, where protein coating enhances biocompatibility.

\section{Pulmonary dose and clearance of MSNs}

The pulmonary dose of MSN-AVI particles at the three time points was determined by quantifying the fluorescent signal of the particles in three pulmonary compartments, namely homogenized lung tissue (after BAL), BAL fluid (BALF) and BAL cells. Using gravimetric analysis of the instillation wear prior and after instillation, we determined that $87.8 \pm 3.5 \mu \mathrm{g}$ and $17.6 \pm 0.6 \mu \mathrm{g}$ of the nominally applied $100 \mu \mathrm{g}$ and $20 \mu \mathrm{g}$ MSN dose was delivered to the lungs, respectively. It is important to note that while the absolute pulmonary dose (in $\mu \mathrm{g}$ ) determines the toxicological (and pharmacological) response, the pulmonary clearance (removal) and biodistribution of particles is typically expressed in terms of relative dose, i.e. pulmonary dose normalized to applied dose (here: 87.8 or $17.6 \mu \mathrm{g})$. For the following, we refer to the pulmonary dose as the relative dose. As seen in Fig. 3A, the pulmonary dose slowly decreased from $80.1 \%$ of the applied dose at day 1 to $55.5 \%$ at day 7 , indicating relatively slow clearance kinetics (for both 20 and $100 \mu \mathrm{g}$ MSN doses), which can be attributed to macrophage clearance from the alveolar surface. ${ }^{36}$ By fitting the measured total lung dose to an exponential function (relative dose $=0.851 \mathrm{e}^{-0.061 t}$, where $t$ represents time in units of days), the alveolar clearance half time was determined as 8.7 days. During this period, the MSN dose decreased by $50 \%$ corresponding to an average clearance rate of $5.7 \%$ per day. Consequently, we found a relatively high retention of MSN-AVI particles in pulmonary tissue at day 7 after instillation (56\% of the applied dose). When extrapolating the exponential fit curve to $t=0$ (time point of MSN application), one obtains a relative dose of 0.851 , i.e. macrophage clearance can only account for $85.1 \%$ of the actually applied dose. The residual $14.9 \%$ can be attributed to a faster clearance mechanism known as mucociliary clearance from the bronchial region, which is typically completed within $1 \mathrm{~d}$ after application. ${ }^{36}$

The phagocytic clearance of MSNs was also studied on cytospins of BAL cells by counting the amount of MSN agglomerates larger than $1 \mu \mathrm{m}$ (the smallest detectable cross sectional area) per nuclei on cytospins (i.e. the amount of $>1 \mu \mathrm{m}$ MSN agglomerates over the total amount of counted nuclei per image). After 1 day, more agglomerates of MSN-AVI could be observed in the BAL compared to $\mathrm{MSN}^{-\mathrm{NH}_{2}}$ (Fig. 3C). The ratio of estimated MSN agglomerates per nuclei showed a transient increase at day 3 which declined again by day 7 after treatment (Fig. 3D). The observed difference in clearance rate may be explained by the fact that at day 1 the number of macrophages in $\mathrm{MSN}-\mathrm{NH}_{2}$ treated lungs had declined to about one third of MSN-AVI treated mice due to the pronounced phagocyte toxicity of $\mathrm{MSN}-\mathrm{NH}_{2}$. However, the macrophage number recovered to similar levels of MSN-AVI treated mice at the later time points (Fig. 1C).

Particle uptake specifically by alveolar macrophages was confirmed, by counterstaining with a macrophage marker (MAC3, green channel). All detected MSN-AVI were found in macrophage marker positive cells with round nuclei, but not in polymorphonuclear neutrophils, thus significant uptake by other BAL cells could be excluded (Fig. 2E). The type A scavenger receptor MARCO (macrophage receptor with collagenous structure) has been described to function as an important receptor of alveolar macrophages mediating the interaction with unopsonized particles such as silica or bacteria. ${ }^{38}$ Since the expression of MARCO is restricted to subpopulations of tissue macrophages and particularly high in spleen marginal zone, resident peritoneal, and alveolar macrophages but is low in monocyte derived macrophages, ${ }^{39}$ the choice of cells studied is very important. Surface modification, such as by avidin might reduce the interaction of MSN particles with these scavenger receptors and thus effect a rapid phagocytosis and related clearance by alveolar macrophages. In summary, MSN-AVI particles showed the bimodal lung clearance kinetics (i.e. slow alveolar macrophage clearance, and fast mucociliary clearance from the bronchial region) which is typical for particle removal from the lungs. ${ }^{36}$ The MSN-AVI had a slow clearance kinetics which is particularly promising for pulmonary therapy as it increases the residence time and hence the bioavailability of the encapsulated drugs.

\section{Particle distribution in the lung}

The distribution of MSNs in the lungs was assessed by preparing cryo-sections of (non-lavaged) lungs, which were analysed by immunofluorescence. ATTO 633 labelled MSNs could easily be detected by confocal microscopy on $14 \mu \mathrm{m}$ thick lung cryosections (red channel, Fig. 4A). The MSNs were distributed evenly over the tissue, also reaching the alveolar region of the lung. Furthermore, the nanoparticles showed widespread and significant accumulation in the lungs for at least 7 days, confirming our previous dosimetry findings (Fig. 4A and S5 $\dagger$ ).

After 1 day, many particle agglomerates could be observed, while after 3 and 7 days, fewer but bigger MSN-AVI agglomerates remained (Fig. 4A lower panel). High magnification images indicated that a fraction of the MSN-AVI particles remained on the epithelium, evidence of which was still present after 7 days (Fig. 4B and S5 $\dagger$ ). In contrast, only limited evidence was obtained that $\mathrm{MSN}-\mathrm{NH}_{2}$ particles were taken up 
A)

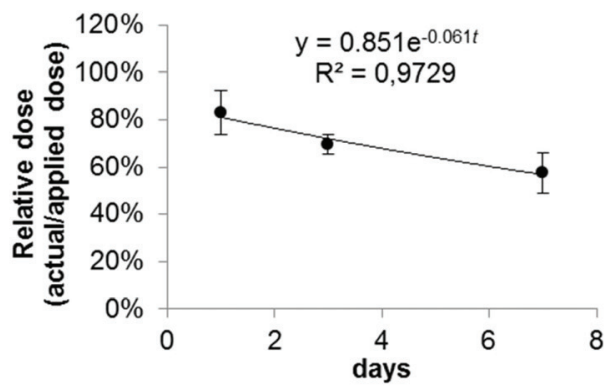

C)

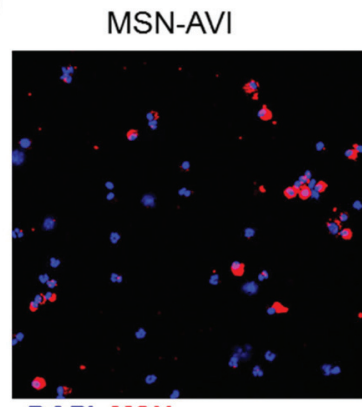

DAPI, MSNs

E)

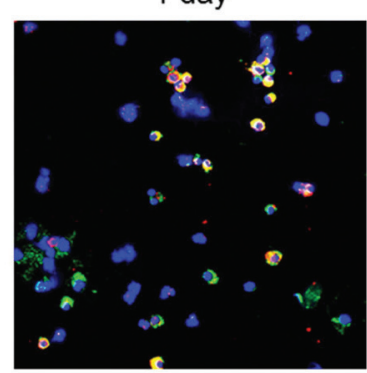

DAPI, MSNs, MAC3

3 days
B)

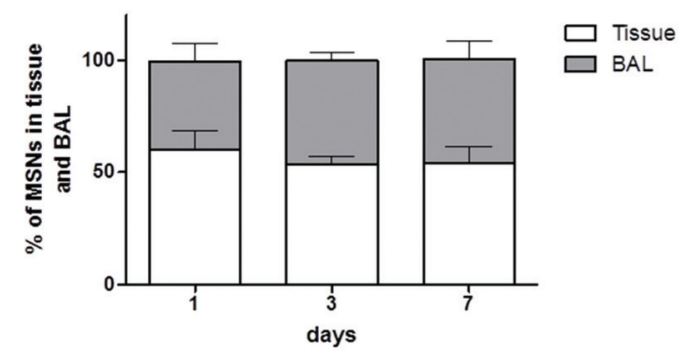

D)
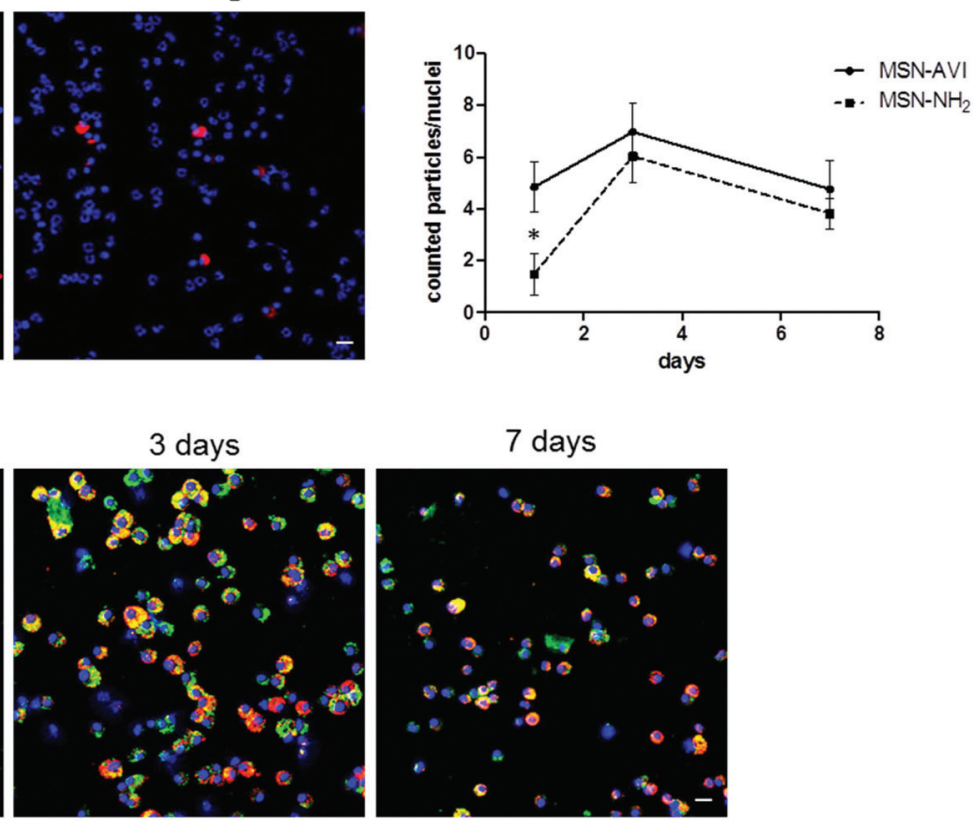

Fig. 3 Pulmonary dose and clearance of MSNs in the lungs of Balb/c mice up to seven days after particle instillation. (A) Temporal decrease of pulmonary dose (normalized to applied dose) and derived exponential clearance kinetics of MSN-AVI particles up to day 7 ( $n=3$ ). (B) MSN-AVI particle distribution in lung tissue and BAL over time ( $n=3)$. (C) MSN-AVI and MSN-NH $\mathrm{N}_{2}$ particles (red) distribution in BAL cells (nuclei DAPI staining, blue) after 1 day. (D) Quantification of particle clearance in BAL cells depicted as the number of MSN agglomerates (larger than $1 \mu \mathrm{m}$ ) per counted nuclei ( $n=3$ animals, 2 images per animal). (E) MSN-AVI particles (red) in BAL recovered cells with macrophage marker co-staining (MAC3, green). Cell nuclei are shown in blue (DAPI), ATTO 633 labelled MSNs are shown in red. Scale bar is $20 \mu \mathrm{m}$.

by epithelial cells. In fact, when investigating cryo-sections at higher magnifications, we mainly observed macrophage uptake of $\mathrm{MSN}^{-\mathrm{NH}_{2}}$ particles (Fig. 4C). Furthermore, z-stack images of non-phagocytized $\mathrm{MSN}-\mathrm{NH}_{2}$ particles revealed that these nanoparticles appear to associate with the tissue rather than being internalized into the cells (Fig. 4C, right panel). Counterstaining the cryo-sections with epithelial type I and II cell markers, podoplanin (T1 $\alpha)$ and pro-surfactant associated protein C (Pro-SPC), respectively, revealed that MSN-AVI particles are internalized by epithelial lung cells (Fig. 4D, E and $\mathrm{S} 4 \dagger$ ) as confirmed by confocal $z$-stack imaging (Fig. 5A). To investigate the cell specific uptake further, we prepared cocultures of a murine alveolar macrophage cell line (MH-S) and an alveolar epithelial cell line (MLE-12) to study the fate of the particles in an in vitro model. Clearly distinguishable cell populations could be observed by fluorescence-activated cell sorting (FACS) analysis excluding leakage of the dye to the other cell type at the studied time-points (Fig. S7 $\dagger$ ). Co-cultures indeed showed enhanced MSN-AVI particle uptake in epithelial cells compared to macrophage cell uptake (Fig. 5B, left panel). In contrast, $\mathrm{MSN}-\mathrm{NH}_{2}$ particles showed almost exclusively uptake in macrophages in the same co-culture set-up (Fig. 5B, right panel).

In summary, cell type specific immunostainings revealed that $\mathrm{MSN}-\mathrm{NH}_{2}$ particles are preferentially internalized by macrophages in vivo and in vitro and that this leads to macrophage cytotoxicity. In contrast, MSN-AVI particles were - in addition to being phagocytically cleared by macrophages also efficiently internalized by alveolar epithelial type 1 and type 2 cells, as investigated in lung tissue cryo-sections. More- 
A)

B)

D)
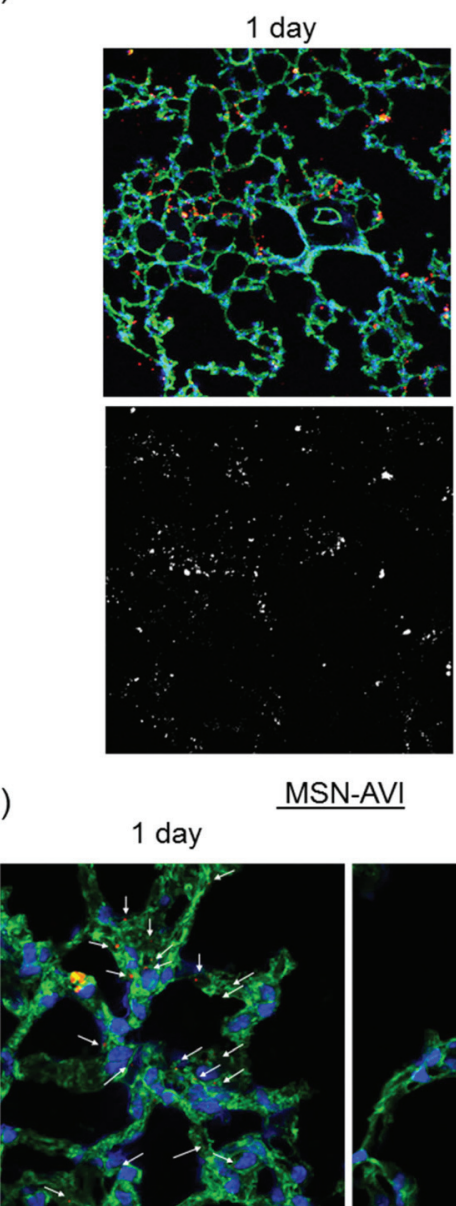

DAPI, Phalloidin, MSNs

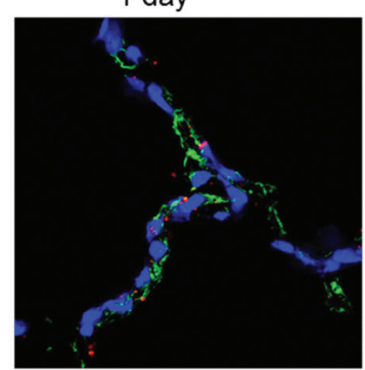

DAPI, MSNs, T1 $\alpha$
MSN-AVI
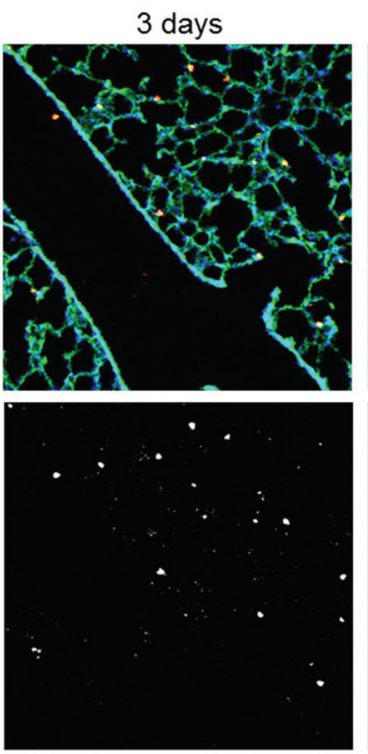

C)

7 days
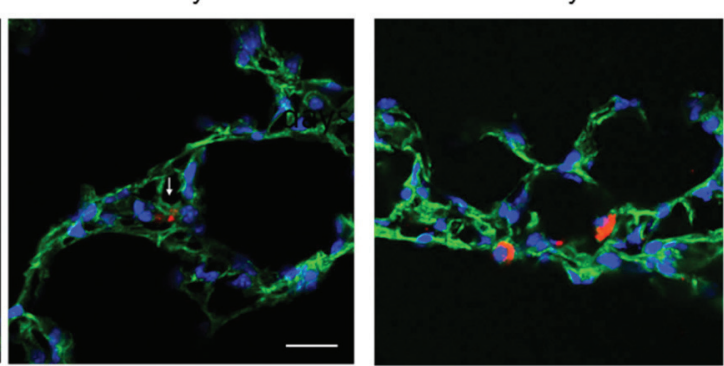

E)
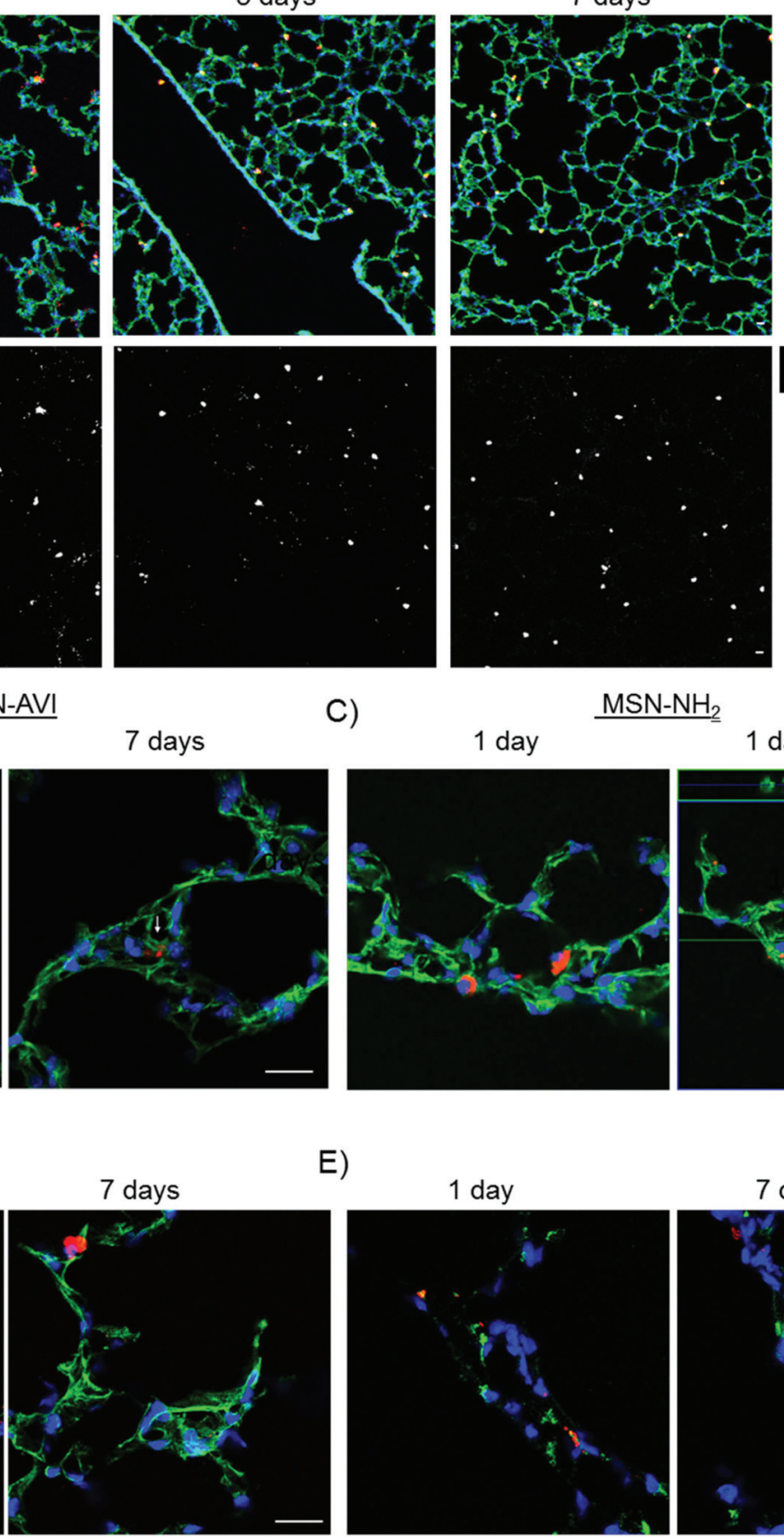

DAPI,

Phalloidin,

MSNs

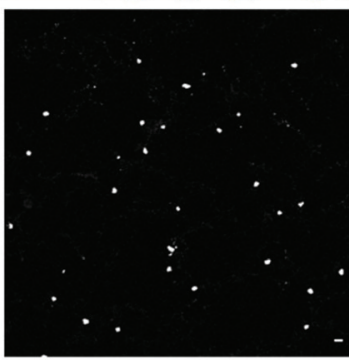

\section{MSNs}

DAPI, MSNs, pro-SPC

Fig. 4 MSN distribution in mouse lungs up to 7 days after particle instillation. (A) Lung cryo-slices of Balb/c mice exposed to $100 \mu \mathrm{g}$ MSN-AVI for 1 , 3, or 7 days with phalloidin co-staining (upper panel) and the same images showing only MSNs (lower panel, MSNs are shown in white to increase the contrast). Lung cryo-slices of Balb/c mice exposed to (B) $100 \mu \mathrm{g} \mathrm{MSN-AVI} \mathrm{for} 1$ day (left) and 7 days (right)(arrowheads represent locations of MSN-AVI) and (C) $100 \mu \mathrm{g} \mathrm{MSN-NH}$ for 1 day, (D) $100 \mu \mathrm{g} \mathrm{MSN-AVI} \mathrm{with} \mathrm{epithelial} \mathrm{cell} \mathrm{type} 1$ co-staining (T1 $\alpha$, green) for 1 day (left) and 7 days (right), and (E) $100 \mu \mathrm{g} \mathrm{MSN-AVI} \mathrm{with} \mathrm{epithelial} \mathrm{cell} \mathrm{type} 2$ co-staining (pro-SPC, green) for 1 day (left) and 7 days (right). Cell nuclei are shown in blue (DAPI), ATTO 633 labelled MSNs are shown in red. Images are representative images for $n=4$ animals. Scale bar is $20 \mu \mathrm{m}$.

over, MSN-AVI also showed higher uptake in epithelial cells compared to macrophage cell uptake in an in vitro co-culture model. Previous studies have shown that cellular uptake of MSNs is highly dependent on surface charge, surface modifications, and is cell type-specific. ${ }^{40,41}$ Furthermore, several in vitro studies have shown that the cell uptake of MSNs is celltype-, dosage- and time-dependent. ${ }^{42,43}$ Interestingly, it has been reported that amination of MSN particles prevents particle endocytosis in T-lymphocyte cells (Jurkat) and in a human neuroblast cell line. ${ }^{36,41}$ These findings highlight the 
A)

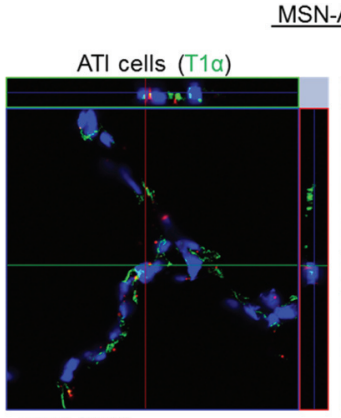

DAPI, MSNs

B)
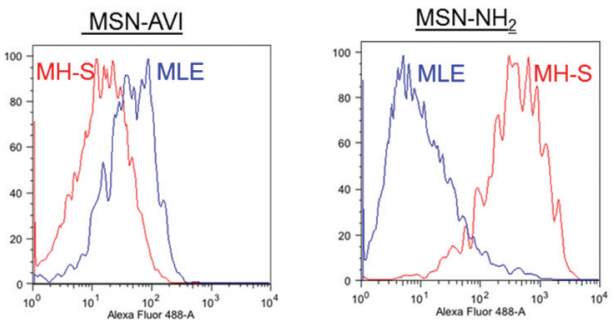

Fig. 5 Cellular uptake comparison of MSN-AVI and MSN-NH2. (A) $Z$-stack images (63x objective) of cryo-slices of Balb/c mice exposed to MSN-AVI for 1 day after instillation, co-stained with alveolar epithelial cell type 1 (ATI) marker ( $T 1 \alpha$, left image) and alveolar epithelial cell type 2 (ATII) marker (pro-SPC, right image) in green. DAPI staining in blue, scale bar is $20 \mu \mathrm{m}$. (B) Representative (of $n=3$ ) FACS histograms of cocultures of MH-S and MLE-12 cells, showing differential cell uptake of MSN-AVI and MSN- $\mathrm{NH}_{2}$ particles. MSN particles (labelled with Alexafluor 488) uptake could be quantified by gating MLE-12 DiD labelled cell population $(630 \mathrm{~nm})$ and non-labelled $\mathrm{MH}-\mathrm{S}$ cell population.

importance of outer surface modifications and their interactions with different cell types, but also that avidin coating may be a good strategy to overcome issues related to macrophage uptake and particle toxicity.

\section{Conclusions}

In this study, we investigated the relevance of avidin-capped MSNs (MSN-AVI) for pulmonary therapy by looking at their pulmonary distribution, clearance rate, cell specific uptake, and induction of inflammatory response after direct (intratracheal) instillation in the lungs of mice. In a recent publication we showed that these particles are promising carriers for lung cancer therapy as they could release a combination of drugs efficiently and tumor-selectively in in vitro and in human and mouse ex vivo lung tissue. ${ }^{6}$ Since MSNs allow for multiple functionalizations, which have been found to be important for their bioresponse, we also included non-capped (only aminofunctionalized; $\mathrm{MSN}-\mathrm{NH}_{2}$ ) particles in this study. We show that MSN avidin surface modification had an effect not only on toxicity, but also on cell specific uptake and tissue distribution in the lungs. In particular, non-capped $\left(\mathrm{MSN}-\mathrm{NH}_{2}\right)$ particles were found to be cytotoxic to macrophages, caused an enhanced inflammatory response, and were hardly taken up by epithelial cells. In contrast, MSN-AVI particles co-localized with alveolar epithelial type 1 and type 2 cells in the lung tissue and showed preferential epithelial cell uptake in in vitro co-cultures. These findings, in combination with the low surface specific toxicity, wide distribution of the particles in the mouse lungs and slow clearance rate is promising for the treatment of chronic lung diseases such as COPD, IPF, and lung cancer, where (alveolar) epithelial cells play an important role in the pathogenesis. Moreover, the inflammatory potential of drug delivery particles is most critical in inflammatory lung diseases such as asthma and COPD, due to additive effects leading to worsening of the symptoms. In this context, the observation that the dose of $1 \mathrm{mg} \mathrm{kg}{ }^{-1}$ of MSN-AVI did not cause any detectable inflammatory response is particularly promising for treatment of these devastating lung diseases. Thus, we believe that avidin-coated MSNs offer potential for inhalative application as therapeutic drug carriers in chronic lung diseases. In addition, the finding that surface modifications greatly affect toxicity and cell type specific uptake highlights the importance of these types of studies for future development of nanomedicines.

\section{Acknowledgements}

We thank the Alexander von Humboldt foundation for providing funding for S. H. van Rijt. Furthermore, financial support from the Nanosystems Initiative Munich (NIM) and the DFG (SFB 749) are gratefully acknowledged.

\section{References}

1 C. M. Dawidczyk, C. Kim, J. H. Park, L. M. Russell, K. H. Lee, M. G. Pomper and P. C. Searson, J. Controlled Release, 2014, 187, 133-144.

2 C. A. Schutz, L. Juillerat-Jeanneret, H. Mueller, I. Lynch, M. Riediker and N. Consortium, Nanomedicine, 2013, 8, 449-467.

3 S. H. van Rijt, T. Bein and S. Meiners, Eur. Respir. J., 2014, 44, 765-774.

4 C. Argyo, V. Weiss, C. Bräuchle and T. Bein, Chem. Mater., 2014, 26(1), 435-451.

5 V. Cauda, A. Schlossbauer, J. Kecht, A. Zurner and T. Bein, J. Am. Chem. Soc., 2009, 131, 11361-11370.

6 S. H. van Rijt, D. A. Bölükbas, C. Argyo, S. Datz, M. Lindner, O. Eickelberg, M. Koenigshoff, T. Bein and S. Meiners, ACS Nano, 2015, 9(3), 2377-2389.

7 H. K. Na, M. H. Kim, K. Park, S. R. Ryoo, K. E. Lee, H. Jeon, R. Ryoo, C. Hyeon and D. H. Min, Small, 2012, 8, 17521761.

8 J. Lu, Z. Li, J. I. Zink and F. Tamanoi, Nanomedicine, 2012, 8, 212-220.

9 H. Liu, T. Liu, X. Wu, L. Li, L. Tan, D. Chen and F. Tang, Adv. Mater., 2012, 24, 755-761.

10 Y. Chen, H. Chen and J. Shi, Adv. Mater., 2013, 25, 31443176. 
11 Q. He, Z. Zhang, F. Gao, Y. Li and J. Shi, Small, 2011, 7, 271-280.

12 X. Huang, L. Li, T. Liu, N. Hao, H. Liu, D. Chen and F. Tang, ACS Nano, 2011, 5, 5390-5399.

13 Y. S. Lin and C. L. Haynes, J. Am. Chem. Soc., 2010, 132, 4834-4842.

14 Y. Zhao, X. Sun, G. Zhang, B. G. Trewyn, I. I. Slowing and V. S. Lin, ACS Nano, 2011, 5, 1366-1375.

15 O. Taratula, O. B. Garbuzenko, A. M. Chen and T. Minko, J. Drug Targeting, 2011, 19, 900-914.

16 J. Lu, M. Liong, Z. Li, J. I. Zink and F. Tamanoi, Small, 2010, 6, 1794-1805.

17 N. Kupferschmidt, X. Xia, R. H. Labrador, R. Atluri, L. Ballell and A. E. Garcia-Bennett, Nanomedicine, 2013, 8, 57-64.

18 H. Vallhov, N. Kupferschmidt, S. Gabrielsson, S. Paulie, M. Stromme, A. E. Garcia-Bennett and A. Scheynius, Small, 2012, 8, 2116-2124.

19 T. Yu, K. Greish, L. D. McGill, A. Ray and H. Ghandehari, ACS Nano, 2012, 6, 2289-2301.

20 S. P. Hudson, R. F. Padera, R. Langer and D. S. Kohane, Biomaterials, 2008, 29, 4045-4055.

21 A. Beyerle, A. Braun, A. Banerjee, N. Ercal, O. Eickelberg, T. H. Kissel and T. Stoeger, Biomaterials, 2011, 32, 86948701.

22 E. F. Burguera, M. Bitar and A. Bruinink, Eur. Cells Mater., 2010, 19, 166-179.

23 T. Stoeger, C. Reinhard, S. Takenaka, A. Schroeppel, E. Karg, B. Ritter, J. Heyder and H. Schulz, Environ. Health Perspect., 2006, 114, 328-333.

24 O. M. Merkel, A. Beyerle, D. Librizzi, A. Pfestroff, T. M. Behr, B. Sproat, P. J. Barth and T. Kissel, Mol. Pharm., 2009, 6, 1246-1260.

25 A. A. Gotz, A. Vidal-Puig, H. G. Rodel, M. H. de Angelis and T. Stoeger, Part. Fibre Toxicol., 2011, 8, 28.

26 N. Barapatre, P. Symvoulidis, W. Moller, F. Prade, N. C. Deliolanis, S. Hertel, G. Winter, A. O. Yildirim, T. Stoeger, O. Eickelberg, V. Ntziachristos and O. Schmid, J. Pharm. Biomed. Anal., 2015, 102, 129-136.

27 J. M. Anderson, A. Rodriguez and D. T. Chang, Semin. Immunol., 2008, 20, 86-100.
28 T. Sager, M. Wolfarth, M. Keane, D. Porter, V. Castranova and A. Holian, Nanotoxicology, 2015, 1-11, DOI: 10.3109/ 17435390.2015.1025883.

29 W. S. Cho, R. Duffin, F. Thielbeer, M. Bradley, I. L. Megson, W. Macnee, C. A. Poland, C. L. Tran and K. Donaldson, Toxicol. Sci., 2012, 126, 469-477.

30 M. Simko, D. Nosske and W. G. Kreyling, Int. J. Environ. Res. Public Health, 2014, 11, 4026-4048.

31 L. M. Costantini, R. M. Gilberti and D. A. Knecht, PLoS One, 2011, 6, e14647.

32 W. J. Sandberg, M. Lag, J. A. Holme, B. Friede, M. Gualtieri, M. Kruszewski, P. E. Schwarze, T. Skuland and M. Refsnes, Part. Fibre Toxicol., 2012, 9, 32.

33 S. Bhattacharjee, D. Ershov, K. Fytianos, J. van der Gucht, G. M. Alink, I. M. Rietjens, A. T. Marcelis and H. Zuilhof, Part. Fibre Toxicol., 2012, 9, 11.

34 H. W. Chiu, T. Xia, Y. H. Lee, C. W. Chen, J. C. Tsai and Y. J. Wang, Nanoscale, 2015, 7, 736-746.

35 P. Ruenraroengsak and T. D. Tetley, Part. Fibre Toxicol., 2015, 12, 19.

36 W. G. Kreyling, M. Semmler-Behnke, S. Takenaka and W. Moller, Acc. Chem. Res., 2013, 46, 714-722.

37 D. A. Kuhn, D. Vanhecke, B. Michen, F. Blank, P. Gehr, A. Petri-Fink and B. Rothen-Rutishauser, Beilstein J. Nanotechnol., 2014, 5, 1625-1636.

38 M. S. Arredouani, A. Palecanda, H. Koziel, Y. C. Huang, A. Imrich, T. H. Sulahian, Y. Y. Ning, Z. Yang, T. Pikkarainen, M. Sankala, S. O. Vargas, M. Takeya, K. Tryggvason and L. Kobzik, J. Immunol., 2005, 175, 60586064.

39 S. Mukhopadhyay, Y. Chen, M. Sankala, L. Peiser, T. Pikkarainen, G. Kraal, K. Tryggvason and S. Gordon, Eur. J. Immunol., 2006, 36, 940-949.

40 T. H. Chung, S. H. Wu, M. Yao, C. W. Lu, Y. S. Lin, Y. Hung, C. Y. Mou, Y. C. Chen and D. M. Huang, Biomaterials, 2007, 28, 2959-2966.

41 Z. Tao, B. B. Toms, J. Goodisman and T. Asefa, Chem. Res. Toxicol., 2009, 22, 1869-1880.

42 J. L. Vivero-Escoto, I. I. Slowing, B. G. Trewyn and V. S. Lin, Small, 2010, 6, 1952-1967.

43 F. Tang, L. Li and D. Chen, Adv. Mater., 2012, 24, 1504-1534. 